
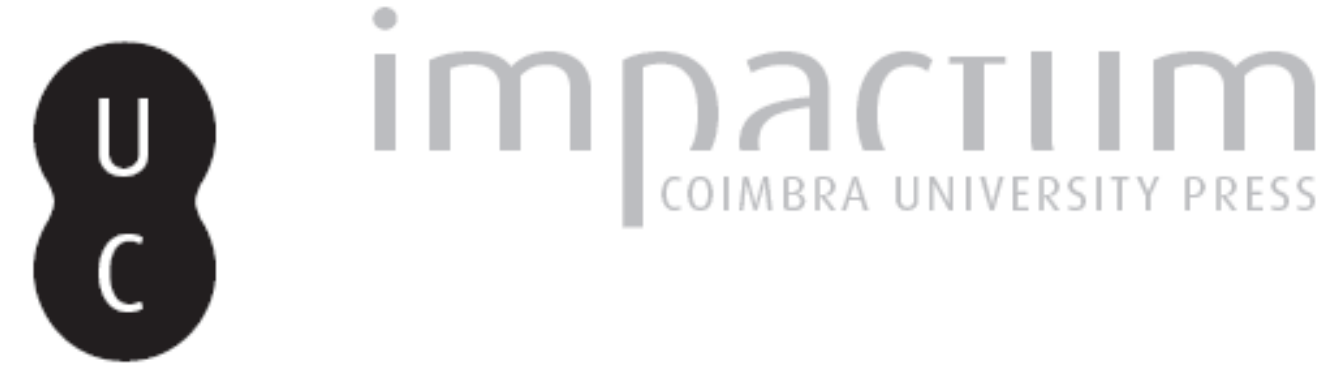

\title{
Tráfico de crianças para fins de exploração da mendicidade: contextualização do problema, (algumas) medidas de protecção das vítimas e lacunas do sistema português
}

\author{
Autor(es): $\quad$ Medina, Ângela
}

Publicado por: Imprensa da Universidade de Coimbra

URL

persistente:

URI:http://hdl.handle.net/10316.2/43062

DOI:

DOI:https://doi.org/10.14195/1647-6336_17_3

\section{Accessed : $\quad$ 26-Apr-2023 09:34:05}

A navegação consulta e descarregamento dos títulos inseridos nas Bibliotecas Digitais UC Digitalis, UC Pombalina e UC Impactum, pressupõem a aceitação plena e sem reservas dos Termos e Condições de Uso destas Bibliotecas Digitais, disponíveis em https://digitalis.uc.pt/pt-pt/termos.

Conforme exposto nos referidos Termos e Condições de Uso, o descarregamento de títulos de acesso restrito requer uma licença válida de autorização devendo o utilizador aceder ao(s) documento(s) a partir de um endereço de IP da instituição detentora da supramencionada licença.

Ao utilizador é apenas permitido o descarregamento para uso pessoal, pelo que o emprego do(s) título(s) descarregado(s) para outro fim, designadamente comercial, carece de autorização do respetivo autor ou editor da obra.

Na medida em que todas as obras da UC Digitalis se encontram protegidas pelo Código do Direito de Autor e Direitos Conexos e demais legislação aplicável, toda a cópia, parcial ou total, deste documento, nos casos em que é legalmente admitida, deverá conter ou fazer-se acompanhar por este aviso.

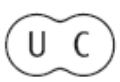




\section{DEBATER \\ A EUROPA}

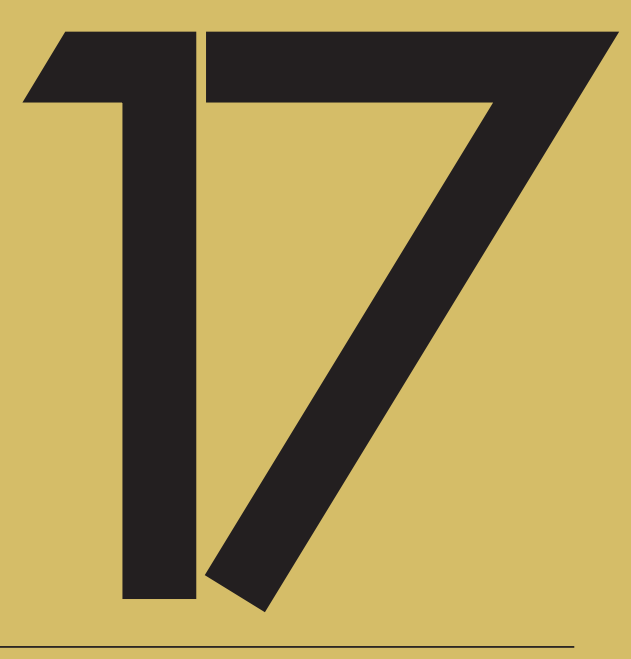

jul-dez 2017

UNIÃO EUROPEIA E O COMBATE AO
TRÁFICO DE SERES HUMANOS

THE EUROPEAN UNION AND COMBATING

TRAFFICKING IN HUMAN BEINGS 


\title{
Tráfico de crianças para fins de exploração da mendicidade: contextualização do problema, (algumas) medidas de protecção das vítimas e lacunas do sistema português
}

Trafficking of children for exploitation of begging: contextualization of the problem, (some) measures to protect victims and gaps in the Portuguese system in Human Beings: a traumatic event. From prevention to network intervention: What role for health services

\author{
Ângela Medina, Master \\ ISBB-UC \\ E-mail: a.guida@hotmail.com
}

\section{Resumo}

A transposição de diversos instrumentos de direito internacional e europeu para o ordenamento jurídico português levou à recente criminalização da mendicidade forçada infantil, passando a mesma a ser punida como tráfico de pessoas.

Pretendemos aqui prestar o nosso contributo para o conhecimento deste fenómeno em Portugal, mediante a análise de algumas das suas causas e origens, assim como de algumas medidas de protecção que a legislação nacional consagra para as crianças traficadas, centrando-se na sua aplicação e eficácia.

Palavras-chave: Tráfico de Seres Humanos; Mendicidade Forçada Infantil; Crianças; Vítimas; Medidas de Protecção.

\section{Abstract}

The transposition of several instruments of international and European law into the Portuguese legal system has led to the recent criminalization of forced child begging, which started to be sentenced as human trafficking. We intend here to make our contribution to the knowledge concerning this issue in Portugal. In order to do so, we studied some of its causes and origins, as well as the measures that national legislation takes to protect trafficked children, focusing not only on its application but also on their effectiveness. 
Keywords: Trafficking in Human Beings; Forced Child Begging; Children; Victims; Protective Acts.

\section{Nota introdutória}

A defesa dos direitos humanos afigura-se hoje como uma tarefa hercúlea, na medida em que com os processos de globalização adveio a rápida circulação de capitais, pessoas, bens e serviços, o que conduziu quer ao aparecimento de uma crise económica mundial, quer à facilitação do desenvolvimento da criminalidade organizada transnacional.

Como reflexo do impacto negativo desta crise económica e da actividade criminosa, com o acentuar das desigualdades sociais e com o aparecimento de novos tipos de criminalidade, o tráfico de seres humanos tem-se manifestado como um problema em expansão, estimando a Organização Internacional do Trabalho (OIT) que entre 2002 e 2011 tenham sido traficadas mundialmente 20,9 milhõees de pessoas, de entre as quais 5,5 milhões de crianças. ${ }^{1,2}$

A mendicidade forçada infantil - tema que aqui nos propomos contextualizar e, ainda que de forma resumida, desenvolver - apresenta-se, assim, como um dos fins do tráfico de crianças, sendo as mais vulneráveis a este tipo de exploração aquelas que provêm de famílias em situações de pobreza e com condições de vida precárias, permeáveis à estigmatização e à marginalização.

\section{O Tráfico de Seres Humanos: enquadramento legal e factores de desenvolvimento.}

O Tráfico de Seres Humanos" (TSH) é visto hoje como sendo a "escravatura dos tempos modernos" $"$ e, como tal, considerado como um enorme retrocesso civilizacional, representando um "fenómeno devastador e humilhante para toda a humanidade", que afecta todos os países à escala mundial (seja como países de origem, de trânsito ou de destino), sendo facilitado pela globalização e, de forma inerente, pelo desenvolvimento tecnológico.

1 COMISSÃO EUROPEIA, EUROSTAT, Trafficking in human beings, 2013, p. 18;

2 Ao longo deste texto, optaremos pela utilização do conceito de "criança" em detrimento da concepção de "menor" prevista no art. $1600^{\circ}$ do Código Penal, porquanto consideramos que, quer em face do art. 1. ${ }^{\circ}$ da Convenção dos Direitos da Criança, quer do n. ${ }^{\circ} 6$ do art. 2. ${ }^{\circ}$ da Directiva 2011/36/UE, de 5 de Abril - que a definem como sendo qualquer pessoa com idade inferior a 18 anos, - é a terminologia juridicamente mais correcta para o desenvolvimento do tema a que nos propomos.

3 A tipificação legal desta conduta encontra-se prevista no art. $1600^{\circ}$ do $\mathrm{CP}$, sendo a mesma punida a título de tráfico de pessoas. Todavia, sendo expressões sinónimas, utilizamos aqui designação tráfico de seres humanos, porquanto se trata da tradução literal da expressão inglesa trafficking in human beings;

4 ALBANO, Manuel, Tráfico de Seres Humanos, a escravatura dos tempos modernos, p. 5;

5 COSTA, José de Faria, A Globalização e o tráfico de seres humanos (o pêndulo trágico da história e o direito penal), p. 260 ; 
O Protocolo relativo à Prevenção, à Repressão e à Punição do Tráfico de Pessoas, em especial, Mulheres e Crianças, adoptado pela Assembleia Geral das Nações Unidas, em 15 de Novembro de 2000 (Protocolo de Palermo), ${ }^{6}$ no seu art. 3. ${ }^{\circ}$, define o tráfico de seres humanos como:

"o recrutamento, o transporte, a transferência, o alojamento ou o acolhimento de pessoas, recorrendo à ameaça ou ao uso da força ou a outras formas de coacção, ao rapto, à fraude, ao engano, ao abuso de autoridade ou de situação de vulnerabilidade ou à entrega ou aceitação de pagamentos ou benefícios para obter o consentimento de uma pessoa que tem autoridade sobre outra para fins de exploração. A Exploração deverá incluir, pelo menos, a exploração da prostituição de outrem ou outras formas de exploração sexual, o trabalho ou serviços forçados, a escravatura ou práticas similares à escravatura, a servidão ou a extracção de órgãos" [(al. a) considerando-se, nestes termos, que o consentimento prestado pela vítima é irrelevante (al. c) e que] "o recrutamento, o transporte, a transferência o alojamento ou o acolhimento de uma criança para fins de exploração deverão ser considerados tráfico de pessoas, " [mesmo que não envolvam os meios considerados na al. a)].

Em suma, para que possa falar-se em tráfico de seres humanos, é necessário que se preencham três elementos cumulativos: a existência de uma acção (como o recrutamento, o transporte, entre outras.), com recurso a determinados meios, os quais servirão para coagir a vítima (como a ameaça ou o uso de força), com a intenção de a explorar (por exemplo, sob a forma de exploração sexual ou laboral).

Segundo os dados da UNODC, 7 o tráfico de seres humanos é mais frequentemente cometido no seio da criminalidade organizada ${ }^{8}$ de carácter transnacional, sabendo-se que, seis em cada dez vítimas são traficadas internacionalmente (isto é, com recurso a

6 Protocolo adicional à Convenção das Nações Unidades Contra a Criminalidade Organizada Transnacional, adoptada pela Assembleia Geral das Nações Unidas em 15 de Novembro de 2000.

7 A Agência das Nações Unidas contra as Drogas e o Crime (UNODC) foi fundada em 1997, e tem como objectivo auxiliar os Estados-Membros na sua luta contra as drogas ilícitas, a criminalidade e o terrorismo. O seu trabalho está baseado nas áreas da saúde, da justiça e da segurança pública e as suas principais atribuições são: "[o desenvolvimento de] trabalho normativo, para ajudar os Estados na ratificação e na implementação dos tratados internacionais, e no desenvolvimento de suas legislações nacionais em matérias de drogas, criminalidade e terrorismo, além de oferecer serviços técnicos e operacionais para órgãos de execução e controle estabelecidos pelos tratados internacionais, [a] pesquisa e análise, para aumentar o conhecimento e a compreensão dos problemas relacionados às drogas e à criminalidade e para ampliar a definição de políticas e de estratégias com base em critérios baseados em evidências; [e a] assistência técnica, por meio de cooperação internacional, para aumentar a capacidade dos Estados-membros em oferecer uma resposta às questões relacionadas às drogas ilícitas, ao crime e ao terrorismo," informação disponível em https://www.unodc.org/lpo-brazil/pt/sobre-unodc/index.html;

8 Sobre o conceito de Criminalidade organizada transnacional vide art. 2. ${ }^{\circ}$ da Convenção das Nações Unidas contra a Contra a criminalidade Organizada Transnacional; 
movimentação geográfica e passagem de, pelo menos uma fronteira) e que uma em cada três vítimas é traficada no seu próprio país (tráfico interno). ${ }^{9}$

Estas organizações criminosas, souberam, assim, tirar partido da facilidade de movimentação de pessoas, bens e capitais à escala mundial, propiciadas pela globalização da economia, actuando a um nível transnacional e caracterizando-se pela posse de uma estrutura polivalente e flexível, equiparável à de uma empresa (em muitos casos multinacional, assente na durabilidade, no desenvolvimento e na divisão científica do trabalho), o que facilita a sua adaptação e expansão a novos mercados e zonas geográficas, ${ }^{10} \mathrm{com}$ vista à maximização do lucro, ${ }^{11}$ assim obrigando à internacionalização da política criminal.

O desenvolvimento desta criminalidade organizada transnacional, munida de vastos recursos humanos e económicos, fez com que os Estados tomassem consciência da sua falta capacidade de resposta para este problema, na medida em que os meios de prevenção e repressão da actividade criminosa se desenvolvem a um ritmo mais lento do que esta, ${ }^{12}$ que prospera e se organiza "nas lacunas do controlo social internacional e na esteira da mundialização da economia."13

Por outro lado, e mais uma vez como consequência da globalização da economia, a facilidade das trocas comerciais, a rápida circulação de capitais favorecida pelos avanços nas telecomunicações ${ }^{14}$ e nos meios de transporte e o desenvolvimento dos meios informáticos, ${ }^{15}$ traduziram-se num aumento dos fluxos de bens (quer lícitos, quer ilícitos) ${ }^{16}$ e levaram "ao

9 NAÇÕES UNIDAS. UNODC, Global Report on Trafficking in Persons, 2014, p. 8;

10 CARRAPIÇO, Helena, O Crime Organizado Transnacional na Europa: Origens, Práticas e Consequências, p. 7;

11 Segundo Susan Strange, o lucro sobe sempre que a prestação de um determinado bem ou serviço (como as drogas, a prostituição e a pornografia, entre outros), é declarado ilegal, apud, SARAGOÇA, Cristina Maria R. C. G. Saragoça, Portugal nas Redes Internacionais de Tráfico de Seres Humanos (Crianças), p. 40;

12 SOUSA, Alfredo José de, A criminalidade transnacional na União Europeia. Um Ministério Público Euroeu?, p. 79;

13 CUSSON, Maurice, Criminologia, p. 229;

14 A EUROPOL considera a Internet "(...) como uma ferramenta de comunicação, fonte de informação, mercado, campo de recrutamento e de serviços financeiros, (...) facilita todos os tipos de criminalidade organizada offline, incluindo a extracção de drogas ilícitas, a síntese e tráfico, tráfico de seres humanos para exploração sexual, a migração ilegal, fraudes e propoganda em massa, fraude de impostos, contrafacção do euro e o comércio de armas proibidas de fogo", in SOUSA, Francisco de; FERREIRA, José; AGOSTINHO, Nuno, A ameaça do crime organizado transnacional em Portugal, p. 23;

15 Segundo José Braz, "a crescente e irreversivel interdependência das economias nacionais, alicerçada na facilidade e rapidez com que actualmente se desenvolvem as trocas comerciais e as operações financeiras assentes em sofisticados meios tecnológicos e informáticos, se por um lado trouxe inquestionáveis benefícios para a sociedade em geral, por outro, estimulou e potenciou o desenvolvimento de novas actividades criminais," Investigação Criminal. A organização, o método e a prova. Os desafios da nova criminalidade, p. 261.

A título exemplificativo, a ONU identifica a roubo de identidade, o tráfico internacional e a pornografia infantil como alguns dos crimes cujo desenvolvimento a internet tem permitido, apud, SOUSA, Francisco de; FERREIRA, José; AGOSTINHO, Nuno, ob cit., p. 23-24;

16 VASCONCELOS, Ricardo Manuel Costa, Criminalidade organizada em Portugal. Um estudo exploratório, p. 33; 
exacerbamento de assimetrias no desenvolvimento, especialmente nas denominadas relações Norte/Sul." ${ }^{\prime 17}$ Com efeito,

“convulsões políticas, instabilidade social e graves conflitos étnicos no Leste Europeu, bem como os sangrentos conflitos religiosos, pobreza e guerra em África são alguns dos factores que mudaram recentemente o mundo e concorreram para tornar a Europa do Sul numa área de atração imigratória [na década de oitenta], tanto para imigrantes económicos como para refugiados."'18

No que concerne aos efeitos dos processos de Globalização em Portugal, e em particular, no que respeita à sua entrada na União Europeia em 1986, com as consequentes alterações ao nível das "formas tradicionais de regulação social, económica, política e cultural", 19 cedo se percebeu a sua reduzida capacidade de acompanhar o desenvolvimento dos restantes países e a fragilidade do seu tecido económico, o que fez com que as exigências de competitividade e internacionalização político-económica se mostrassem de difícil concretização.

Inserido numa União Europeia que tem vindo, desde o início deste século, a perder importância no plano mundial - em face da crise financeira prolongada de alguns dos seus Estados-Membros e da emergência das economias da Àsia (de entre as quais a Índia e a China) e do Hemisfério Sul (como é o caso do Brasil) no plano económico internacional Portugal viu-se confrontado com a "pior crise das últimas décadas", ${ }^{20} \mathrm{com}$

“a (...) estagnação da economia e a incapacidade de acompanhar, de forma perene e consistente, os ritmos de crescimento e desenvolvimento da União Europeia; o aumento exponencial do desemprego nas últimas décadas; os baixos salários; um tecido empresarial pouco competitivo; um défice das contas públicas que atinge em 2010, de acordo com os dados do Instituto Nacional de Estatística (INE, Abril de 2011), os 9,1\% a par do fortíssimo endividamento externo das empresas e do país." ${ }^{21}$

Desta forma, a globalização afirma-se em Portugal como um factor de potenciação da fragilidade económica do país, colocando em evidência as suas lacunas ao nível da competitividade externa, o que acarreta diversas consequências para a economia nacional, no que concerne às dificuldades de sustentação das empresas já existentes bem como de

17 DAVIN, João, A criminalidade organizada transnacional. A cooperação Judiciária e Policial na UE., p. 10;

18 BAGANHA, Maria Ioannis, A cada Sul o seu Norte. Dinâmicas migratórias em Portugal, in SANTOS, Boaventura de Sousa, Globalização. Fatalidade ou Utopia?, p. 137;

19 SANTOS, Boaventura de Sousa, apud, Adilson Genari; Cristina Albuquerque, ob cit., p. 3;

20 LEITE, António Nogueira, A internacionalização da Economia Portuguesa, p. 120;

21 GENARI, Adilson; ALBUQUERQUE, Cristina, ob cit., p. 3; 
atracção de investimento directo estrangeiro (IDE), cujos efeitos vão desde a formação de capital, à criação de emprego, à melhoria da estrutura produtiva e exportadora, ao acesso a novas tecnologias de produção e de gestão e ainda à resolução problemas relacionados com a escassez de capital nacional. ${ }^{22}$

Estas dificuldades reflectem-se, desde logo, nos níveis de desemprego nacional ${ }^{23}$, no aumento do número de portugueses que se vêem forçados a emigrar ${ }^{24}$, assim como na precarização do emprego (determinados, designadamente, pela restrição dos direitos dos trabalhadores), o que se traduz na vulnerabilidade das suas condições de vida e no surgimento de novas formas de exclusão social, "decorrentes da privação dos benefícios sociais funcionalmente associados ao emprego e à contribuição." 25

Por via da precarização das condições de trabalho, da neutralização da segurança económica, da exploração de imigrantes irregulares, do surgimento de casos de escravatura e de tráfico de seres humanos (nomeadamente, para exploração da mão-de-obra), a globalização procede a uma reconfiguração do emprego que tende a conduzir a novas situações de pobreza. ${ }^{26}$ Uma pobreza muitas vezes silenciosa e "envergonhada", de trabalhadores com baixos salários e sem protecção social, mas também de pessoas que anteriormente se encontravam inseridas social e profissionalmente. ${ }^{27}$

A pobreza, identificada pela sua face mais visível, a das necessidades materiais, ${ }^{28}$ pode definir-se como sendo uma "situação de privação resultante da falta de recursos," ${ }^{29}$ isto é, as pessoas não têm capacidade para gerar o rendimento necessário à aquisição de bens e serviços que satisfaçam as suas necessidades humanas básicas e lhes garantam uma qualidade de vida digna, como é o caso da saúde, da alimentação, da educação, habitação, entre outros. ${ }^{30}$

22 LEITE, António Nogueira, ob cit., pp. 129-130;

23 Segundo os dados do Eurostat, a taxa de desemprego em Portugal fixou-se em 12,2\% em Dezembro de 2010, tendo atingido o seu pico em Janeiro de 2013, altura em que se registou uma taxa de 17,5\%. Já em Abril de 2015, a taxa de desemprego desceu para os $13,0 \%$, in, COMISSÃO EUROPEIA. EUROSTAT, Taxa de Desemprego, corrigida de sazonalidade;

24 Segundo os dados do Observatório da Emigração, em 2010 verificou-se a saída de 70.000 portugueses do país, número que aumenta em 2013, ano em que se verifica que 110.000 portugueses se viram forçados a emigrar, in, PORTUGAL. Direcção-Geral dos Assuntos Consulares e das Comunidades Portuguesas. Observatório da Emigração, Emigração Portuguesa, Relatório Estatístico 2014, p. 36;

25 CALEIRAS, Jorge, Globalização, trabalho e desemprego. Trajectórias de exclusão e estratégias de enfrentamento, p. 8;

26 GENARI, Adilson; ALBUQUERQUE, Cristina, $o b$ cit., p. 7;

27 Idem, p. 10;

28 PERISTA, Pedro; BAPTISTA, Isabel, Pobreza em Portugal: retrato de um fenómeno insuspeitadamente extenso, p. 3 ;

29 COSTA, Alfredo Bruto da, et. al., Um olhar Sobre a Pobreza: vulnerabilidade e exclusão social no Portugal contemporâneo, p. 26;

30 Nas palavras de Yasbek, "são pobres aqueles que, de modo temporário ou permanente, não têm acesso a um minimo de bens e recursos sendo, portanto, excluídos em graus diferenciados da riqueza social”, apud, GOMES, Mônica Araújo; PEREIRA, Maria Lúcia Duarte, Família em situação de vulnerabilidade social: uma questão de políticas públicas, p. 359; 
A situação financeira de Portugal bem como a precariedade e a fragilidade laborais ${ }^{31}$ vieram a deteriorar-se ainda mais, fruto do colapso do sistema financeiro mundial determinado pela falência do banco de negócios americano Lehman Brothers, em 2008, após o qual surgiram sucessivos pacotes de austeridade, enquanto "processo de implementação de políticas e de medidas económicas que conduzem à disciplina, ao rigor e à contenção económica, social e cultural," ${ }^{32}$ fazendo recair sobre as pessoas os custos da crise, por via de cortes salariais, perda de benefícios sociais, entre outros. ${ }^{33}$

A "Grande Recessão" entrou então nas preocupações do Conselho Europeu, e a resposta da União Europeia à situação passou por várias fases. Em Portugal, em concreto, numa fase inicial (denominada de "fase financeira"), com início no último trimestre de 2008, o principal objectivo foi o reforço das instituições financeiras. A esta, seguiu-se uma "fase económica", com início em Janeiro de 2009, na qual se visava a criação de medidas de iniciativa ao investimento e ao emprego. Por fim, a fase orçamental, iniciada em Março de 2010 (que ficou marcada pelos diversos Programas de Estabilidade e Crescimento, cujo objectivo consistia na contenção do défice e controlo da dívida pública), obrigou à adopção de diversas medidas, como a redução de despesas com prestações sociais, o aumento das taxas de impostos, entre vários outros. ${ }^{34}$

Como consequência, verificou-se um aumento continuado do desemprego, ${ }^{35} \mathrm{acom}-$ panhado do aumento do número de pessoas privadas de acesso ao subsídio de desemprego e ao rendimento social de inserção. ${ }^{36}$ A estes efeitos, soma-se ainda o "recuo da provisão pública e a restrição do acesso nos transportes, comunicações, serviços de saúde e de educação," 37 bem como um aprofundamento das desigualdades sociais, acompanhado de um decréscimo do rendimento das famílias e da diminuição do consumo privado.

31 "Em Portugal, o contexto da austeridade dá origem a situações de insegurança que são toleradas ou suportadas pelos indivíduos, dado não terem alternativa possível. A situação da insegurança atrás descrita combina-se com as faces do medo e da precariedade, de perder o emprego, da necessidade de assegurar um salário, facilitando-se a troca de direitos pela subsistência. (...) A taxa de desemprego alimenta a ideia de que devido à dificuldade de encontrar um emprego, a qualidade do trabalho seja sacrificada, constituindo a precariedade mais uma variável de ajustamento para a saida da crise," in FERREIRA, António Casimiro, Sociedade da Austeridade e direito de trabalho de exceção, p. 61;

32 Idem, p. 11;

33 Idem, p. 12;

34 CALDAS, José Castro, O impacto das medidas "anti-crise" e a situação social e de emprego. Portugal, p. 1;

35 Em Janeiro de 2009, estimava-se que existissem 464 mil pessoas desempregadas, número que se situava em 720 mil, em Novembro de 2011, in CALDAS, José de Castro, ob cit., p. 9;

36 "O número de desempregados sem acesso ao subsídio passou de 237 mil para 410 mil entre Janeiro de 2009 e Novembro de 2011 e o número de beneficiários do Rendimento Social de Inserção, que havia aumentado de 328 mil, em Janeiro de 2008, para 440, em Maio de 2010, baixou para 332 mil em Novembro de 2011, in CALDAS José de Castro, ob cit., p. 9;

37 CALDAS, José de Castro, ob cit., p. 9 
De facto, com o pedido de ajuda externa em Abril de 2011 e com as subsequentes negociações com a troika, as palavras de ordem passaram a ser "austeridade" e "sacrifício", assim se contribuindo para o aumento das desigualdades sociais e para o agudizar da crise social. ${ }^{38}$ Note-se que, já em 2010, Portugal era um dos países mais assimétricos da Europa, em que $12 \%$ da população empregada se encontrava em risco de pobreza, ${ }^{39}$ e onde "o rendimento auferido pelos 20\% mais ricos é 6,1 vezes superior ao dos 20\% mais pobres, " ${ }^{40}$ valores apenas suplantados pela Letónia, pela Roménia e pela Bulgária, que apresentavam, respectivamente, taxas de 7.3, 7.0 e 6.5, dados que classificavam Portugal como o 4. ${ }^{\circ}$ país com maiores diferenças de rendimento. ${ }^{41}$

Em face do desemprego estrutural que afecta a sociedade portuguesa, que no segundo trimestre de 2014 atingiu os 13,9\% ${ }^{42}$, assiste-se a um "enfraquecimento da condição salarial"43 cujas consequências se repercutem quer ao nível colectivo, provocado pelo aumento da procura do sistema de protecção social, quer ao nível individual, motivado pela instabilidade pessoal. ${ }^{44}$

A situação de desemprego prolongada e a manutenção do estado de pobreza, ${ }^{45}$ associadas a outros factores dos quais é exemplo o baixo nível de habilitações literárias, são propícias à criação de situações de risco, podendo conduzir a ciclos viciosos de exclusão social, particularmente nos segmentos mais vulneráveis da sociedade, ${ }^{46}$ pois a inclusão dos indivíduos na sociedade depende também da posição que os mesmos possuem relativamente ao domínio económico, quer no que concerne aos sistemas geradores de rendimentos - que para a maioria das famílias é o mercado de trabalho -, quer no que toca à capacidade de aquisição de bens e serviços. ${ }^{47}$

38 Segundo o estudo The Distributional Effects of austerity measures: a comparision of six EU Countries (2011), em comparação com outros países da UE, nomeadamente, a Grécia, a Espanha, a Irlanda, o Reino Unido e a Estónia, "Portugal é o único país que tem exigido mais sacrifícios aos mais pobres do que aos mais ricos," in FERREIRA, António Casimiro, ob cit., p. 50;

39 CARMO, Renato Miguel do, apud, FERREIRA, António Casimiro, ob cit., p. 49;

40 Ibidem;

41 Ibidem;

42 Dados do Instituto Nacional de Estatística (INE), disponíveis em http://www.ine.pt/xportal/ xmain? xpid $=$ INE\&xpgid=ine_indicadores\&indOcorrCod $=0005599 \&$ selTab $=$ tab0;

43 CALEIRAS, Jorge, ob cit., p. 6;

44 Ibidem;

45 Acresce que, "no contexto do crescente tumulto financeiro e insegurança económica, há cada vez mais famílias a recorrer à assistência social como a única esperança para assegurar os mínimos recursos para sobreviver. Para além destas, existem ainda aquelas familias que, por viverem numa pobreza envergonhada, consequência de uma pobreza recente, não se dirigem aos serviços disponíveis e vivem isolada e degradantemente a sua pobreza," in, HELENO, Armandina, Todos têm direito a uma vida digna!, p. 24;

46 HELENO, Armandina, ob cit., p. 4;

47 COSTA, Alfredo Bruto da, ob cit., pp. 66-67; 


\section{Crianças vítimas de exploração da mendicidade: o problema e as suas causas. ${ }^{48}$}

A desestruturação familiar, motivada pelo rompimento dos laços familiares, é uma das consequências da crise sócio-económica, ${ }^{49}$ cujas maiores vítimas tendem a ser as crianças, muitas delas forçadas a abandonar as escolas e enviadas para as ruas para ajudar ao sustento da família. ${ }^{50}$

Estima-se que existam, actualmente, 25 milhões de crianças em situação de risco de pobreza ou de exclusão social na União Europeia, o que corresponde a uma em cada quatro crianças. ${ }^{51}$

Segundo a EAPN e a Eurochild Task Force, a pobreza infantil ocorre quando os rendimentos e os recursos disponíveis para o crescimento das crianças "são de tal forma inadequados que as excluem de ter uma qualidade de vida considerada aceitável na sociedade em que vivem, e não sejam capazes de assegurar o seu desenvolvimento e bem-estar ${ }^{52}$ social, emocional e físico",53.

Em 2011, Portugal tinha 412.000 crianças em risco de pobreza, o que significa que $21,8 \%$ das crianças nacionais viviam em agregados com um rendimento per capita inferior a 416,00€ por mês. ${ }^{54}$ Os apoios sociais (nomeadamente, os subsídios de desemprego e os abonos de família, entre outros), influenciam positivamente estes números, atendendo a que, antes da sua transferência para as famílias, a percentagem de crianças em risco de pobreza aumenta de $21,8 \%$ para $33 \%{ }^{55}$

No entanto, apesar da importância dos apoios sociais na atenuação da pobreza infantil e de Portugal ter uma elevada taxa de risco de pobreza e de exclusão social relativamente

48 Nos termos art. $7 .^{\circ}$ n. ${ }^{\circ} 1$ da Lei n. ${ }^{\circ} 67 / 98$, de 26 de Outubro, “é proibido o tratamento de dados pessoais referentes a convicções filosóficas ou políticas, filiação partidária, fé religiosa, vida privada e origem racial ou étnica", pelo que procuraremos aqui evitar, tanto quanto nos for possível, fazer menção racial ou étnica que viole esta disposição, sendo que a utilização que aqui fizermos de tais menções será baseada em factos advenientes de trabalho de investigação;

49 Segundo a Organização Internacional do Trabalho (OIT), "segurança, liberdade e dignidade constituem uma unidade integrada e interdependente. Nesse sentido, a liberdade só pode existir em concomitância com um certo nível de segurança económica. É esta hipótese de interdependência entre segurança e liberdade que está na base do acesso ao direito a ter uma justa e boa oportunidade de viver uma vida decente e de se afirmar através do trabalho digno." in, FERREIRA, António Casimiro, ob cit., p. 127;

50 GOMES, Mónica Araújo; PEREIRA, Maria Lúcia Duarte, ob cit., p. 360;

51 EAPN, Para o bem-estar das crianças na Europa. Pobreza infantil na UE, p.4;

$52 \mathrm{O}$ "bem-estar” das crianças é definido pelo Consórcio Europeu de Fundações para o Bem-Estar na Europa como " a descoberta do seu potencial através do desenvolvimento físico, emocional e espiritual... em relação a si mesma, aos outros e ao ambiente. (...)A UNICEF identificou seis aspetos diferentes do bem-estar da criança que considera mais importantes. Estes são: o bem-estar material, saúde e segurança, bem-estar educativo, familia e relacionamentos com os outros, comportamentos e riscos, e a subjetividade do bem-estar (isto é, como as crianças se sentem sobre si próprias)" apud EAPN, Para o bem estar das crianças na Europa..., p. 9;

53 idem, p. 8;

54 NAÇÕES UNIDAS. UNICEF, As Crianças e a Crise em Portugal, p. 13;

55 idem, pp. 13-14; 
a outros países da União Europeia, as medidas de austeridade tiveram repercussões a este nível e, entre os anos de 2009 e 2012, foram 546.354 as crianças que perderam o direito ao abono de família, o que representa cerca de $30 \%$ dos beneficiários. ${ }^{56}$

Se, por um lado, o aumento das taxas de pobreza e de desemprego, bem como as condições de trabalho precárias, são factores que criam maiores situações de vulnerabilidade ao tráfico e à exploração, por outro, o impacto negativo da crise económica e financeira, com a implementação das medidas de austeridade que se têm vindo a sentir em Portugal, reflecte-se numa maior desprotecção das crianças e no aumento da sua vulnerabilidade à exploração.

A redução da despesa pública nos sectores relacionados com as crianças e com as suas famílias, ${ }^{57}$ associada ao desemprego e à redução dos rendimentos familiares, além de comprometer bem-estar e desenvolvimento das crianças, culmina muitas vezes num retrocesso cultural, onde estas voltam a ser vistas como fonte de rendimento para as suas famílias, nomeadamente, por via da sua exploração na mendicidade.

A mendicidade é definida pela OIT como "um conjunto de actividades através das quais uma pessoa pede dinheiro a um estranho em razão de ser pobre ou de necessitar de doações de caridade para a sua saúde ou por razões religiosas. ",58

Apesar de em diversos países da União Europeia começar a surgir a criminalização da mendicidade, em Portugal, só por si, ela não constitui um crime. Porém, a utilização de crianças ou de pessoa psiquicamente incapaz na mendicidade é punida nos termos do art. 296. ${ }^{\circ}$ do Código Penal.

O Instituto de Apoio à Criança (IAC) - através do seu Projecto Rua, que visa actuar junto de crianças em risco ${ }^{59}$ que utilizam a rua de forma desacompanhada - identifica três tipos de mendicidade infantil: (1) a mendicidade clássica, com crianças nacionais provenientes de famílias pobres, desestruturadas ou ligadas ao consumo de estupefacientes, que as encaram como fontes de rendimento (designada pushed begging); (2) a mendicidade

56 idem, 53;

57 "O comissário para os Direitos Humanos do Conselho da Europa declarou, em 2012, que as medidas de austeridade implementadas em Portugal afectaram desigualmente os grupos sociais mais vulneráveis, especialmente, as crianças, os mais idosos e a população cigana. Os apoios sociais às crianças foram reduzidos significativamente em 2010 e novamente em 2012, agravando a situação financeira das famílias. No sector da saúde, as taxas cobradas para o acesso a cuidados médicos parecem estar a afectar o acesso das crianças com mais de 12 anos, pondo em questão os direitos de igualdade. As comissões locais de Protecção de Crianças e Jovens observaram um aumento considerável de casos em 2012. No entanto, devido a restrições orçamentais, há a preocupação de que as entidades de primeira linha e as Comissões de Protecção de Crianças possam não funcionar de forma tão plena como anteriormente" in, UNIÃO EUROPEIA. Direcção Geral dos Assuntos Internos. IMPACT, Melhorar e Monitorizar os Sistemas de Protecção Contra o Tráfico e a Exploração de Crianças, p. 33;

58 PORTUGAL. Ministério da Administração Interna. OTSH. Mendicidade Forçada..., p. 6;

59 As crianças traficadas para fins de exploração na mendicidade são consideradas pelo nosso ordenamento jurídico como crianças em risco e em perigo e, como tal, é-lhes aplicável a Lei de Protecção de Crianças e Jovens em Perigo (LPCJP), desde que residam ou se encontrem no território nacional e independentemente da sua nacionalidade - art. $2{ }^{\circ}$ LPCJP; 
infantil, praticada por comunidades estrangeiras provenientes, designadamente, do antigo bloco do Leste, onde as crianças praticam a mendicidade acompanhadas ou vigiadas por adultos (seus familiares ou não) e cujo apogeu se deu em 2005 (designada forcced begging), ${ }^{60}$ (3) e ainda a mendicidade infantil praticada por crianças de rua, que a utilizam como forma de sobrevivência. ${ }^{61}$

Afirmar que uma criança é vítima de tráfico de seres humanos para exploração da mendicidade, ${ }^{62}$ significa dizer que ela é obrigada a mendigar por outras pessoas, a quem entrega todos ou quase todos os proveitos que recebeu, ${ }^{63}$ mediante ameaça de violência ou de outras formas de coacção física ou psicológica, sendo as crianças frequentemente mal-tratadas pelos exploradores (quer porque se recusam a trabalhar, quer porque não conseguem obter os rendimentos esperados) e por vezes até por aqueles a quem pedem esmola, trabalhando horas a fio durante todo o dia. ${ }^{64}$

A mendicidade forçada infantil assume-se, assim, como uma das categorias de trabalho forçado e ainda como uma das piores formas de trabalho infantil, nos termos em que são definidos, respectivamente, pelas Convenções n. ${ }^{\circ} 29$ e 182 da Organização Internacional do Trabalho.

É possível distinguir dois tipos de situações em que as crianças são forçadas a mendigar: em primeiro lugar, as crianças que são exploradas por terceiros (onde se incluem as redes ou associações criminosas, familiares afastados, entre outros.); e, em segundo lugar, as crianças submetidas à mendicidade pelos seus próprios pais ou por quem por elas seja responsável, mediante recurso e/ou ameaça de violência e coerção psicológica. ${ }^{65}$

Embora mereçam tratamentos distintos, porquanto apesar de em ambas as formas de exploração ser cometida uma violação grosseira dos direitos das crianças, ${ }^{66}$ somos em crer que, tal como o afirma Cherneva, as situações em que as crianças são obrigadas a mendigar pelos próprios pais ou por familiares se tratam de tráfico de crianças,

60 No caso da mendicidade infantil, quer a pushed begging quer a forced begging importam situações de risco para a criança e a violação dos seus direitos fundamentais. Porém, a distinção entre as duas realidades torna-se imperativa quer para a compreensão do fenómeno da mendicidade e das suas causas, quer para delimitar estratégias de intervenção, in SANTOS, Elizabeth, Tráfico de Seres Humanos e Mendicidade Forçada, The Third Sector Against Pushed Begging - Relatório Nacional - Portugal, p. 11;

61 idem, pp. 43-45;

62 Segundo o OTSH, são várias as formas que a exploração de crianças na mendicidade pode revestir, desde a venda de pequenos objectos ou tocar instrumentos musicais nas ruas ou nos transportes públicos, in PORTUGAL, Ministério da Administração Interna, OTSH, Mendicidade Forçada..., p. 6;

63 DELAP, Emily, Forced Child Begging. Toolkit for researchers, p. 3;

64 DELAP, Emily, Begging for Change, Research findings and recommendations on forced child begging in Albania/Greece, India and Senegal, p. 1;

65 DELAP, Emily, Forced Child Begging. Toolkit for researchers, p. 3;

66 Cremos, pois, que a exploração da mendicidade por terceiros e a exploração pelos próprios pais deve ser tratada de forma diferente. É para nós evidente que, no primeiro caso, os exploradores deverem ser levados à justiça e responsabilizados. Porém, nas situações em que a mendicidade é praticada como forma de sobrevivência das famílias, a intervenção criminal deverá ser acompanhada de uma intervenção social, que permita a estas famílias uma integração na sociedade e não uma maior estigmatização; 
quer porque os meios utlizados para controlo da vítima são considerados irrelevantes nestes casos e a situação de vulnerabilidade das crianças não lhes dá outra alternativa que não submeter-se à exploração, quer ainda porque os proventos da mendicidade lhe são retirados por quem as explora. ${ }^{67}$

Em países como a França, a Espanha e o Reino Unido, as crianças forçadas a mendigar e os adultos que as acompanham são, esmagadoramente, de etnia cigana, oriundos da Roménia, da Bulgária, da Albânia, do Kosovo e da Eslováquia, o que leva a suspeitar da existência de redes organizadas que movimentam as mesmas vítimas de exploração ou tráfico entre o país de origem e vários países de destino. ${ }^{68}$ Um estudo realizado pelo European Roma Rights Center and People in Need, publicado em 2011, focado em países como a Bulgária, a República-Checa, a Hungria, a Roménia e a Eslovénia, concluiu que 20\% das vítimas de tráfico de etnia cigana entrevistadas eram, à data em que foram traficadas, crianças. ${ }^{69}$

Ainda segundo aquele estudo, "as crianças mais expostas à exploração da mendicidade são aquelas que provém de famílias e comunidades mais pobres, especialmente, aquelas que são alvo de estigmatização, marginalização e discriminação, tais como as famílias ciganas ${ }^{70}$ em certos países da União Europeia, "71 apresentando-se as crianças observadas mal-cuidadas, sujas e com vestuário desadequado às condições atmosféricas. ${ }^{72}$ No entanto, segundo o estudo, não é claro que haja abandono escolar destas crianças, não só porque um número significativo está em idade pré-escolar, mas também porque muitos mendigam fora do horário escolar, ${ }^{73}$ o que é um indicador importante, atendendo a que a falta de acesso à educação é considerada um factor de risco para a as crianças forçadas a mendigar e que esta actividade é também uma causa para que as crianças não frequentem a escola. ${ }^{74}$

Devido à situação de pobreza em que se encontra e por falta de outra alternativa de sobrevivência, por vezes a família inteira dedica-se à mendicidade. Nestes casos, a utilização de crianças para a mendicidade é encarada como estratégia de sobrevivência,

67 Apud ROMÉNIA, National Agency Against Trafficking in Persons, Trafficking in Persons for Begging- Romania Study, p. 7;

68 COMISSÃO EUROPEIA, Report for the Study on Typology and Policy Responses to Child Begging in the $E U$, pp. 7-8;

69 Apud COMISSÃO EUROPEIA, Report for the Study on Typology..., pp. 8, 9;

70 "Porém, atendendo à dimensão da população de etnia cigana na União Europeia, que se estima que varie entre 4,7 e 6,4 milhões e os 10 e 12 milhões de pessoas, apenas uma pequena percentagem está envolvida em actividades relativas à mendicidade" COMISSÃO EUROPEIA, Report for the Study on Typology..., p. 29;

71 ibidem;

72 idem..., pp. 8, 9;

73 ibidem;

74 idem, p. 22; 
sobretudo pelo uso de crianças mais pequenas, que despertam mais facilmente a compaixão das pessoas a quem pedem esmola. ${ }^{75}$

Como tal,

"a avaliação das condições de vulnerabilidade das pessoas que praticam a mendicidade, faz com que a identificação e a assistência adequada das vítimas possam quebrar o ciclo deste tráfico. Se os mendigos puderem ser removidos das ruas e assistidos correctamente, os traficantes perderão os seus lucros e as vitimas podem ser ajudadas a sair do ciclo do tráfico." "76 Estas mudanças deverão começar "pelas estruturas básicas, como alterações sistémicas na educação ou na integração laboral das pessoas mais vulneráveis, melhorando a qualidade de vida, até ao desenvolvimento de programas destinados a aumentar a capacitação e sensibilização das autoridades locais." "77

Do fenómeno do tráfico de crianças para fins de exploração da mendicidade, criminalizada em 2013, por via da alteração ao art. 160. ${ }^{\circ}$ do Código Penal decorrente da Lei n. ${ }^{o}$ 60/2013 de 23 de Agosto (que veio transpor para o ordenamento jurídico português a Directiva 2011/36/UE de 5 de Abril), pouco se sabe.

Pelas suas próprias características, este fenómeno mantém-se no anonimato, desconhecendo-se a sua real dimensão e estimando-se que o número de crianças traficadas seja cinco vezes superior ao número de casos conhecidos. ${ }^{78}$

Sendo a sua criminalização recente, ${ }^{79}$ a sociedade em geral ainda desconhece este problema, ao que se soma a falta de formação específica dos diversos operadores judiciários, órgãos de polícia criminal, instituições, (entre outros) ${ }^{80}$ vindo a ser realçada a inexistência de um sistema integrado de recolha e pesquisa de dados estatísticos entre as entidades com competências na área, como as comissões de protecção de crianças, órgãos judiciários e policiais, serviços de segurança social e de saúde, rede de escolas e Provedoria de Justiça. ${ }^{81}$

75 idem, p. 30;

76 ROMÉNIA, National Agency against Trafficking in Persons, ob. cit., p. 10;

77 idem, p. 11;

78 CONSELHO DA EUROPA. GRETA, Report concerning the implementation of the Council of Europe Convention on Action against Trafficking in Human Beings by Portugal, p. 32;

79 A mendicidade forçada foi criminalizada por via da Lei n. ${ }^{\circ}$ 60/2013, de 23 de Agosto;

80 Para Béatrice Ouin, "as organizações da sociedade civil são quem está em melhor posição para compreender o fenómeno, para ajudar na deteção das vítimas e desenvolver um trabalho de prevenção. A polícia, a justiça, a inspeção do trabalho, etc. são indispensáveis, mas se os serviços estatais fossem capazes, por si só, de erradicar o tráfico de seres humanos, esse fenómeno já teria deixado de existir." In, Parecer do Comité Económico e Social Europeu sobre a Comunicação da Comissão ao Parlamento Europeu, ao Conselho, ao Comité Económico e Social Europeu e ao Comité das Regiões - Estratégia da União Europeia para a Erradicção do Tráfico de Seres Humanos 2012-2016," p. 4;

81 UNIÃO EUROPEIA. Direcção Geral dos Assuntos Internos. IMPACT, ob cit., p. 95; 
Acresce que, por um lado, as situações de pobreza e exclusão social das quais são oriundas as vítimas,

"[os] contextos sociais disfuncionais, [a] negligência, [o] abuso e a violência no âmbito da família ou das instituições, [as] relações de exploração, [a] discriminação e [a] violência com base no género, [a] experiência de vivência ou de trabalho na rua, [as] situações de migração precária elou irregular, [as] aspirações a trabalhar e ganhar dinheiro e [as] oportunidades limitadas para entrar ou permanecer na escola, na formação ou no emprego regular," 82 [ao mesmo tempo que as colocam à margem da sociedade, constituem factores de risco de exploração para as crianças].

Por outro lado, a exploração da mendicidade infantil é uma prática enraizada em determinadas culturas (nomeadamente, das etnias ciganas oriundas de países Leste Europeu) ${ }^{83}$, sendo as crianças exploradas pelos próprios pais ou por familiares próximos, o que lhes causa receio e dificuldades para chegar até às autoridades e denunciar a sua situação.

Também a facilidade de movimentação das redes de tráfico coloca dificuldades ao nível da sua detecção e da sinalização das crianças traficadas, que além de serem na sua maioria estrangeiras (tendo assim de ser ultrapassada a barreira linguística, com as consequentes dificuldades ao nível da recolha de prova e de indícios e com obstáculos à criação de empatia entre a criança e as autoridades), nem sempre sabem identificar os países por onde passaram.

\section{O conceito de exploração de menor ${ }^{84}$ na mendicidade: algumas medidas de protec-} ção previstas e lacunas do sistema português.

O esforço legislativo que se tem verificado a nível mundial e europeu na criação de instrumentos de tutela dos direitos das crianças culminou no surgimento de um conjunto de instrumentos de direito internacional cuja importância se tem vindo a acentuar ao longo do tempo.

Também o ordenamento jurídico português tem vindo a desenvolver medidas tendentes à protecção das crianças (em geral), com grandes avanços relativamente à protecção daquelas que são vítimas de tráfico, no seguimento do que é imposto pela legislação

82 UNIÃO EUROPEIA. Direcção Geral dos Assuntos Internos. IMPACT, ob cit., p. 16;

83 Segundo Parecer do Comité Económico Social Europeu relativo à Estratégia da União Europeia para a Erradicação do TSH, "A luta contra a mendicidade forçada praticada por crianças ciganas deve ser parte integrante da estratégia europeia de integração dos ciganos", OUIN, Béatrice, ob cit., p. 5;

84 Utilizamos aqui a terminologia do artigo $160{ }^{\circ}$ do Código Penal, mas consideramos que teria sido mais correcta a utilização do conceito de "criança" como sendo qualquer pessoa com idade inferior a 18 anos, tal como é definido quer pelo art. 1. ${ }^{\circ}$ da CDC, quer pelo n. 6 do art. 2. ${ }^{\circ}$ da Directiva 2011/36/UE; 
internacional, algumas vezes adiantando-se a ela e, por outras, indo até mais além do que ela prevê.

$\mathrm{O}$ art. 69. ${ }^{\circ}$ da CRP, consagra o direito das crianças à protecção, quer pelo Estado, quer pela própria sociedade (cidadãos e instituições sociais), com vista ao seu desenvolvimento integral, ${ }^{85}$ "contra todas as formas de abandono, de discriminação e de opressão $e$ contra o exercício abusivo da autoridade da família e nas demais instituições", devendo o Estado assegurar "especial protecção às crianças órfãs, abandonadas ou por qualquer forma privadas de um ambiente familiar normal", proibindo ainda o trabalho de menores em idade escolar.

Por seu turno, a UE reconhece os sistemas de protecção direccionados para as crianças, garantindo a interacção e a coordenação multidisciplinar, factores fundamentais para atender às necessidades de diversos grupos de crianças, designadamente, daquelas que são vítimas de tráfico de seres humanos. ${ }^{86}$

Referimos anteriormente que a legislação portuguesa é, por vezes, inovadora relativamente à legislação internacional. Da análise da Directiva 2011/36/UE e do art. 160 . $^{\circ}$ do Código Penal, é possível concluir que este possui um âmbito de protecção mais alargado do que aquela, na medida em que, para que uma situação possa ser considerada como mendicidade forçada infantil não é necessário que se verifiquem os requisitos do trabalho ou serviços forçados, como é exigido pela referida Directiva. E nesta medida, somos tentados a concluir que, qualquer situação em que uma criança seja forçada a mendigar, se enquadra no âmbito do art. $160 .^{\circ}$ e, portanto, deve ser punida a título de tráfico de pessoas, independentemente de ser explorada por terceiros ou por quem seja por ela responsável.

A Directiva 2011/36/UE prevê, nos seus arts. $13 .^{\circ}$ a $16 .^{\circ}$ diversas medidas de assistência, apoio e protecção às crianças vítimas de TSH, fundadas no seu "superior interesse", o qual deverá ser considerado o principio norteador. Na sua avaliação - e segundo o Comentário Geral n. ${ }^{\circ} 14$ de 2013 do Comité pelos Direitos das Crianças - devem ser tidos em conta: as opiniões da criança, a sua identidade, a preservação do ambiente familiar e a manutenção das relações, o cuidado, a protecção e a segurança da criança, a situação de vulnerabilidade, o direito à saúde e o direito à educação da criança ${ }^{87}$

Destacamos aqui o art. $14 .^{\circ}$, onde é colocada como prioridade a protecção e a segurança das crianças traficadas, pensadas quer para o plano imediato, quer para o seu futuro.

85 Segundo Gomes Canotilho e Vital Moreira, “a noção constitucional de desenvolvimento integral (n. ${ }^{\circ} 1$ in fine) - que deve ser aproximada da noção de «desenvolvimento da personalidade (art. 26. ${ }^{\circ}-2$ ) - assenta em dois pressupostos: por um lado, a garantia da dignidade da pessoa humana (cfr. art. 1. ${ }^{\circ}$ ), elemento "estático», mas fundamental para o alicerçamento do direito ao desenvolvimento; por outro lado, a consideração da criança como pessoa em formação, elemento dinâmico, cujo desenvolvimento exige o aproveitamento de todas as suas virtualidades" in, CANOTILHO, Gomes; MOREIRA, Vital, Constituição da República Portuguesa Anotada, Artigos 1. ${ }^{\circ}$ a 107. , vol. 1, pp. 869-870;

86 Estratégia da UE para a erradicação do TSH 2012-2016;

87 COMISSÃO EUROPEIA. FRA, Guardianship for Children deprived of parental care. A handbook to reinforce guardianship systems to cater for the specific needs of child victims of trafficking, p. 73; 
A Lei de Estrangeiros ${ }^{88}$, no seu art. 114. ${ }^{\circ}$, bem como a Lei de Protecção de Crianças e Jovens em Perigo, ${ }^{89}$ previam já algumas destas medidas, designadamente (e no caso do art. 91. a da LPCJP), o acolhimento/institucionalização urgente.

Á luz da experiência de países como a Bélgica, a Bulgária e a Itália, o acolhimento das crianças vítimas de TSH deve ser feito em instituições especializadas para o efeito, quer pelo especial contexto dos quais elas são provenientes, quer pela necessidade de protecção acrescida relativamente aos traficantes e à prevenção de fugas das instituições, o que importa elevados riscos de voltarem a ser exploradas..$^{90}$

Acontece que, atendendo ao reduzido número de crianças traficadas identificadas oficialmente, as autoridades nacionais entenderam que o acolhimento em centros especializados não se justifica, sendo as crianças desacompanhadas alojadas em centros genéricos que se integram no sistema de protecção de crianças em risco, ${ }^{91}$ podendo ainda as crianças que são filhas de homens/mulheres vítimas de TSH ser acolhidas nos CAP que se lhes destinam.

Como consequência desta falta de acolhimento especializado e demonstrativo desta necessidade, ONG's portuguesas relataram ao GRETA (Group of Experts on Action against Trafficking in Human Beings) que não possuem condições de protecção e segurança adequadas no caso de crianças traficadas, dando conta de uma situação em que duas crianças foram entregues pela instituição à guarda da qual estavam confiadas aos traficantes que se apresentaram como seus familiares. ${ }^{92}$

Os artigos $16^{\circ}{ }^{\circ} .^{\circ} 3$ e $14 .^{\circ}$ n. ${ }^{\circ} 2$ da Directiva 2011/36/UE referem a necessidade de os Estados-Membros garantirem a nomeação de um tutor para a criança não acompanhada que seja vítima de TSH, apesar de a União Europeia não definir o que entende como tal, nem as suas funções concretas. ${ }^{93}$

Esta necessidade da nomeação de um tutor para a criança desacompanhada tem vindo a ser apontada por diversos outros instrumentos de direito ao nível internacional e europeu, designadamente pela Convenção de Varsóvia (art. 10. ${ }^{\circ}$. ${ }^{\circ} 4$ al. a) e pela Directiva 2012/29/UE (art. 24. 'al. b) e n. 60 do Preâmbulo), mediante as denominações de "tutor", "representante legal" ou "representante", entre outras. ${ }^{94}$

Sendo a pessoa com maior proximidade com a criança e o meio de conexão entre esta e diversas instituições, as atribuições do tutor devem centrar-se, essencialmente, na defesa dos princípios fundamentais previstos na Convenção dos Direitos da Criança: salvaguardar

88 Lei n. ${ }^{\circ}$ 23/2007, de 04 de Julho;

89 Lei n. $^{\circ}$ 147/99, de 01 de Setembro, na sua versão actualizada pela Lei n. ${ }^{\circ}$ 142/2015, de 08/09;

90 COMISSÃO EUROPEIA. FRA, Child Trafficking in the European Union. Challenges, perspectives and good practices, p. 15;

91 UNIÃO EUROPEIA. Direcção Geral dos Assuntos Internos. IMPACT, ob cit., p. 74;

92 CONSELHO DA EUROPA. GRETA, $o b$ cit., p. 32

93 COMISSÃO EUROPEIA. FRA, Guardianship for children deprived of parental care..., p. 13;

94 Idem, p. 14; 
o seu superior interesse, enquanto princípio fundamental de todas as decisões que envolvem a criança; assegurar o direito da criança a que as suas opiniões sejam ouvidas, de acordo com a sua idade, o seu desenvolvimento e as suas capacidades; afirmar o direito à vida e ao desenvolvimento físico, mental e psicológico; promover e salvaguardar o direito à não discriminação. ${ }^{95}$

Porém, em Portugal, esta figura do "tutor legal" ainda não foi implementada. A sinalização de uma criança como vítima de tráfico de seres humanos é reportada ao MP, que por sua vez solicita ao tribunal o decretamento de medidas provisórias de protecção, sendo que, sempre que não seja possível encontrar alguém responsável pela criança, o tribunal coloca-a sob a custódia de instituição de acolhimento, a quem caberá agir de acordo com o superior interesse da criança. ${ }^{96}$

Destacamos ainda nesta sede as alterações ao Código de Processo Penal e a criação do Estatuto da Vítima ${ }^{97}$ decorrentes da aprovação da Lei n. ${ }^{\text {0 }}$ 130/2015, de 4 de Setembro. ${ }^{98}$

Por via do aditamento do art. $67^{\circ} \mathrm{A}$ ao CCP, a vítima - entendida como a pessoa singular que sofreu dano directamente causado por acção ou omissão, no âmbito da prática de um crime (n. ${ }^{\circ}$, al. a), i) - é agora vista como sujeito processual, sendo as vítimas de criminalidade violenta e de criminalidade especialmente violenta ${ }^{99}$ sempre consideradas vítimas especialmente vulneráveis, entendendo-se como tal, designadamente, a vítima cuja especial fragilidade resulte da sua idade (a. b) do n..$^{\circ} 1$ do art. 67. ${ }^{\circ}$ A).

Com a entrada em vigor do Estatuto da Vítima, nos termos do seu art. 22. ${ }^{\circ}$, todas as crianças vítimas de crime têm o direito a ser ouvidas no âmbito do processo penal, devendo ser levadas em consideração a sua idade e maturidade, sendo que os seus depoimentos e declarações enquanto vítimas especialmente vulneráveis (quer em razão da idade quer do tipo de crime), são prestadas através de videoconferência ou teleconferência, quando impliquem a presença do arguido.

No que concerne à possibilidade de serem tomadas declarações para memória futura, o artigo 24. ${ }^{\circ}$ do Estatuto da Vítima prevê que a criança vítima de tráfico de seres humanos seja inquirida no decurso do inquérito e que o seu depoimento possa ser levado em conta na fase de julgamento, devendo a tomada de declarações ser efectuada em ambiente informal e reservado, com vista a garantir que as respostas sejam espontâneas e sinceras.

95 Idem, pp. 18-19;

96 CONSELHO DA EUROPA. GRETA, ob cit., p. 32;

97 Que visa assegurar a proteç̧ão e promoção dos direitos das vítimas de criminalidade;

98 A qual transpôs a Directiva 2012/29/UE, do Parlamento Europeu e do Conselho, de 25 de Outubro para o ordenamento jurídico português

99 Nas quais, nos termos do disposto nas als. j) e 1) do art. $1 .^{\circ}$ do CPP se enquadra o tráfico de seres humanos; 


\section{Reflexão Final}

A visão da criança enquanto ser em desenvolvimento, sujeito de direitos consagrados em diversos instrumentos de direito nacional e internacional, impõe aos Estados o dever de a proteger e de pugnar pelo respeito pelos seus direitos, tarefa esta à qual a própria sociedade, em geral, não pode (nem deve) ser alheia.

Neste contexto, tráfico de crianças manifesta-se não só como o resultado de condutas criminosas, mas também como a clara expressão da incapacidade dos Estados de salvaguardarem os seus direitos, na medida em que permitem que sejam elas as maiores vítimas das consequências da crise económica e financeira que se abateu à escala global.

Apesar do esforço legislativo e de criação de medidas de protecção das crianças traficadas que tem sido feito, constata-se que existe ainda um longo caminho a percorrer a nível nacional, porquanto se torna patente a falta de preparação institucional e societária para solucionar a questão, sendo possível apontar lacunas na protecção destas vítimas, das quais destacamos aqui a falta de um sistema de recolha de dados que permita aferir com maior exactidão sobre a dimensão do problema em causa e a falta de casas de acolhimento especializado para as vítimas.

\section{Referências Bibliográficas}

ALBANO, Manuel, Tráfico de Seres Humanos - A escravatura dos tempos modernos, Notícias, [em linha]. [S.L.]:Comissão para a Cidadania e a Igualdade de Género. N. ${ }^{\circ} 89$ (2013). p. 5-8. ISSN 0871-3316. [consult. 01 Jun. 2014]. Disponível na internet: <URL: http://www.igfse.pt/upload/docs/2014/N89TraficoHumano.pdf;

BRAZ, José - Investigação Criminal. A organização, o método e a prova. Os desafios da nova criminalidade. 2. Ed. Coimbra: Almedina, 2010. ISBN 978-972-40-4350-0;

CALDAS, José Castro Caldas - O impacto das medidas "anti-crise" e a situação social e de emprego. Portugal, [em linha]. Comité Económico e Social Europeu. (2013). [consult. 10 Set. 2014]. Disponível na internet: <URL: http://www.eesc.europa.eu/resources/docs/qe-31-12-351-pt-c.pdf;

CALEIRAS, Jorge, Globalização - Trabalho e Desemprego: trajectórias de Exclusão e Estratégias de Enfrentamento, VII Congresso Luso-Afro-Brasileiro de Ciências Sociais, Coimbra 16, 17 e 18 de Setembro de 2004. [em linha]. (2004). [consult. 10 Set. 2014]. Disponível na internet: <URL: http://www.ces.uc.pt/lab2004/inscricao/pdfs/painel11/JorgeCaleiras.pdf;

CANOTILHO, Gomes; MOREIRA, Vital, Constituição da República Portuguesa

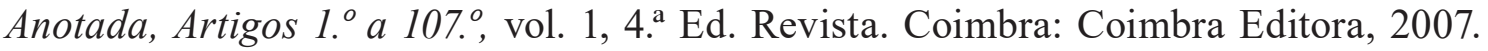
ISBN 978-972-32-1462-8;

CARRAPIÇO, Helena - O Crime Organizado Transnacional na Europa: Origens, Práticas e Consequências, Cadernos do IDN [em linha]. Instituto da Defesa Nacional. 
ISSN 1646-4397. N.o 1 (2006). [consult. 21 Set. 2014]. Disponível na internet: www.idn. gov.pt/publicacoes/cadernos/cadernol_I.pdf;

COMISSÃO EUROPEIA - Report for the Study on Typology and Policy Responses to Child Begging in the EU, [em linha]. (2012). [S.L.]: Comissão Europeia. [consult. 21. Set. 2014]. Disponível na internet: <URL: https://ec.europa.eu/anti-trafficking/sites/antitrafficking/files/report_for_the_study_on_typology_and_policy_responses_to_child_begging_in_the_eu_0.pdf;

COMISSÃO EUROPEIA. EUROSTAT - Taxa de Desemprego, corrigida de sazonalidade, [em linha]. (última act. 9.06.2015). [consult. 22 Jun. 2015]. Disponível na internet:https:// www.google.pt/publicdata/explore?ds=z8o7pt6rd5uqa6_\&met_y=unemployment_rate \&idim $=$ country:pt:es:it\&hl $=$ pt\&dl $=$ pt $\#$ !ctype $=1 \&$ strail $=$ false $\& b c s=d \& n s e l m=h \& m e t$ $\mathrm{y}=$ unemployment_rate\&fdim_y $=$ seasonality:sa\&scale_y=lin\&ind_y $=$ false\&rdim $=$ country_ group\&idim=country:pt\&ifdim=country_group\&hl=pt\&dl=pt\&ind=false

COMISSÃO EUROPEIA. FRA - Child Trafficking in the European Union. Challenges, perspectives and good practices. [em linha]. (2009). ISBN 978-92-9192-399-1. [consult. 27 Set. 2014]. Disponível na internet: <URL: http://fra.europa.eu/sites/default/files/ fra_uploads/529-Pub_Child_Trafficking_09_en.pdf;

COMISSÃO EUROPEIA. FRA - Guardianship for Children deprived of parental care. A handbook to reinforce guardianship systems to cater for the specific needs of child victims of trafficking. [em linha]. (2014). ISBN 978-92-9239-464-6. [consult. 10 Set. 2014]. Disponível na internet: <URL: http://fra.europa.eu/sites/default/files/fra-2014-guardianship-children_en_0.pdf;

CONSELHO DA EUROPA. GRETA - Report concerning the implementation of the Council of Europe Convention on Action against Trafficking in Human Beings by Portugal [em linha]. Strasbourg: Conselho da Europa. (2013). [consult. 1 Set. 2015]. Disponível na internet: <URL https://www.coe.int/t/dghl/monitoring/trafficking/Docs/Reports/ GRETA_2012_17_FGR_PRT_en_with_cmts.pdf;

COSTA, Alfredo Bruto da, et. al., Um olhar Sobre a Pobreza: vulnerabilidade e ex-

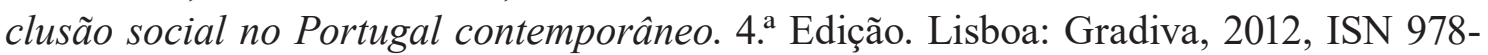
989-616-253-5;

COSTA, José de Faria - A Globalização e o Tráfico de Seres Humanos: o pêndulo trágico da história e o direito penal. Revista de Legislação e Jurisprudência. Coimbra: Coimbra Editora. ISSN 0870-8487. A.136, N. 3944 (2007), p. 258-265;

DAVIN, João - A Criminalidade Organizada Transnacional. A Cooperação Judiciária e Policial na UE. 2. Edição revista e aumentada. Coimbra: Almedina, 2007, ISBN 97-897-240-3256-6;

DELAP, Emily - Begging for Change, Research findings and recommendations on forced child begging in Albania/Greece, India and Senegal, [em linha] (2009). [S.L.]: Anti-Slavery Internacional. ISBN 978-0-900918-73-5. [consult. 21. Set. 2014]. Disponível na internet: <URL: http://www.antislavery.org/includes/documents/cm_docs/2009/b/beggingforchange09.pdf; 
DELAP, Emily - Forced Child Begging. Toolkit for researchers, [em linha]. (2009). [S.L.]: Anti-Slavery Internacional. ISBN 978-0-900918-72-8. [consult. 21 Set. 2014]. Disponível na internet: <URL: http://www.antislavery.org/includes/documents/cm docs/2009/b/beggingforchange_toolkit09.pdf;

EAPN, EUROCHILD - Para o bem estar das crianças na Europa. Pobreza infantil na EU. Explicativo EAPN n. ${ }^{\circ}$ 4. [em linha]. Bruxelas: EAPN, EUROCHILD. [consult. 1 Set. 2015]. Disponível na internet: <URL: http://www.eapn.pt/documentos_visualizar.php?ID=442;

EAPN, EUROCHILD - Para o bem estar das crianças na Europa. Pobreza infantil na EU. Explicativo EAPN n. ${ }^{\circ}$ 4. [em linha]. Bruxelas: EAPN, EUROCHILD. [consult. 1 Set. 2015]. Disponível na internet: <URL: http://www.eapn.pt/documentos_visualizar. php?ID=442;

FERREIRA, António Casimiro - Sociedade da Austeridade e direito de trabalho de exceção. Porto: Vida Económica, 2012, ISBN: 978-972-788-502-2;

GENARI, Adilson; ALBUQUERQUE, Cristina - Globalização, desemprego e (nova) pobreza: Estudo sobre impactes nas sociedades portuguesa e Brasileira, Revista Crítica de Ciências Sociais,[em linha]. N. 92 (2011). [consult. 12 Set. 2014]. Disponível na internet: <URL: http://rccs.revues.org/3970;

GOMES, Mônica Araújo; PEREIRA, Maria Lúcia Duarte - Família em situação de vulnerabilidade social: uma questão de políticas públicas, Ciência Saúde Colectiva, [em linha]. N. ${ }^{\circ} 10$ (2005). [consult. 08 Set. 2014]. Disponível na internet: <URL: www.scielo. br/pdf/csc/v10n2/a13v10n2.pdf;

HELENO, Armandina - Todos têm direito a uma vida digna!, Rediteia, [em linha]. Porto: Rede Europeia Antipobreza - Portugal. N. 43 (2009). p. 24-25. [consult. 21 Set. 2014]. Disponível na internet: $<$ URL: www.eapn.pt/download.php?file=921;

LEAL, Mafalda - Eurochild, A luta pela erradicação da pobreza infantil, Rediteia [em linha]. Porto: Rede Europeia Antipobreza - Portugal. N.o 43 (2009). p. 49-50. [consult. 21 Set. 2014]. Disponível na internet: www.eapn.pt/download.php?file=921;

LEITE, António Nogueira - A internacionalização da Economia Portuguesa, Relações Internacionais, [em linha]. N. ${ }^{\circ}$ 28. (2010). ISSN 1645-9199, pp. 119-132. [consult. 27 Agosto 2015]. Disponível na internet: <URL: http://www.scielo.gpeari.mctes.pt/scielo. php?pid=S1645-91992010000400009\&script=sci_arttext;

NAÇÕES UNIDAS. UNICEF - As crianças e a crise em Portugal. Vozes de Crianças, Políticas Públicas e Indicadores Sociais em 2013. [em linha]. (2013). ISBN 978-97296436-2-0. [consult. 01. Set. 2015]. Disponível na internet: <URL: http://www.observatoriofamilias.ics.ul.pt/index.php/publicacoes/relatorios/100-as-criancas-e-a-crise-em-portugal-vozes-de-criancas-politicas-publicas-e-indicadores-sociais-2013;

NAÇÕES UNIDAS. UNODC - Global Report on Trafficking in Persons, [em linha]. Vienna: United Nations. (2014). ISBN: 978-92-1-133830-0 [consult. 02 Agosto 2014]. Disponível em: http://www.unodc.org/documents/data-and-analysis/glotip/GLOTIP_2014_ full_report.pdf; 
OIUN, Béatrice - Parecer do Comité Económico e Social Europeu sobre a Comunicação da Comissão ao Parlamento Europeu, ao Conselho, ao Comité Económico e Social Europeu e ao Comité das Regiões - Estratégia da União Europeia para a Erradicção do Tráfico de seres humano 2012-2016," [em linha]. (2012). [consult. 01 Set. 2015]. Disponível na internet: <URL: ces1802-2012_00_00_tra_ac_pt.doc;

PERISTA, Pedro; BAPTISTA, Isabel - Pobreza em Portugal: retrato de um fenómeno insuspeitadamente extenso, Revista Angolana de Sociologia, Pobreza e desigualdades sociais, [em linha]. N. ' 9, (2012). p. 153-169; [consult. 12 Set. 2014]. Disponível na internet: <URL: http://ras.revues.org/471;

PIO, Bruno - Pobreza Infantil, Rediteia [em linha]. N. o 43, (2009), p. 42-43. [consult. 21 Set. 2014]. Disponível na internet: $<$ URL: www.eapn.pt/download.php?file=921,

PORTUGAL. Direcção-Geral dos Assuntos Consulares e das Comunidades Portuguesas. Observatório da Emigração - Emigração Portuguesa, Relatório Estatístico 2014. [em linha]. Lisboa: Observatório da Emigração. (2014). [consult. 06 Out. 2014]. Disponível na internet: http://www.observatorioemigracao.secomunidades.pt/np4/?newsId=3924\&fileName=OEm EmigracaoPortuguesa2014_RelatorioEst.pdf;

PORTUGAL. Ministério da Administração Interna. OTSH - Mendicidade Forçada. A face invisivel do Tráfico de Seres Humanos para Exploração Laboral, [em linha]. Lisboa: Observatório do Tráfico de Seres Humanos (2013). ISBN 978-972-597-352-3. [consult. 21 Jun. 2014]. Disponível na internet: www.igualdade.gov.pt/INDEX_PHP/ PT/DOCUMENTACAO/PUBLICACOES/780_MENDICIDADE__FORCADA_A_ FACE_HTM;

ROMÉNIA. National Agency against Trafficking in Persons, Trafficking in Persons for Begging - Romania Study, [em linha]. [S.L.]: National Agency against Trafficking in Persons. (2013). [consult. 01 Jun. 2014]. Disponível na internet: <URL: https://ec.europa. eu/anti-trafficking/sites/antitrafficking/files/trafficking_in_persons_for_begging_-_romania_study_0.pdf;

SANTOS, Elizabeth - Tráfico de Seres Humanos e Mendicidade Forçada,The Third Sector Against Pushed Begging - Relatório Nacional - Portugal. Porto: EAPN Portugal - Rede Europeia Anti-Pobreza, 2014. Depósito Legal n. ${ }^{\circ}$ 382665/14;

SARAGOÇA, Cristina Maria R. C. G. - Portugal nas Redes Internacionais de Tráfico de Seres Humanos (Crianças). [em linha]. Lisboa: Universidade Técnica de Lisboa, Instituto Superior de Economia e Gestão. (2010). Dissertação de mestrado. [consult. 10 Set. 2014]. Disponível na internet: <URL: https://www.repository.utl.pt/handle/10400.5/2923;

SOUSA, Alfredo José de Sousa - A Criminalidade Transnacional na União Europeia. Um Ministério Público Europeu? Coimbra: Almedina, 2005, ISBN 972-402594-2;

SOUSA, Francisco de; FERREIRA, José; AGOSTINHO, Nuno - A ameaça do crime organizado transnacional em Portugal, Revista de Ciências Militares, [em linha]. N. ${ }^{\circ}$, vol. II (2014), pp. 13-39. [consult. 1 Set. 2015]. Disponível na Internet: <URL: http://www. iesm.pt/cisdi/revista/Artigos/R3-1.pdf; 
UNIÃO EUROPEIA. Direcção Geral dos Assuntos Internos. IMPACT, Melhorar e Monitorizar os Sistemas de Protecção Contra o Tráfico e a Exploração de Crianças. Itália: KMOP and Defense for Children Internacional, 2014;

VASCONCELOS, Ricardo Manuel Costa - Criminalidade Organizada em Portugal: um estudo exploratório. [em linha]. Universidade do Minho: Instituto de Ciências Sociais.

(2013). Dissertação de mestrado. [consult. 27 Set. 2014]. Disponível na internet: <URL: repositorium.sdum.uminho.pt/handle/1822/29307;

Artigo Recebido a 14 de dezembro de 2016 | Aceite a 18 de julho de 2017 